\title{
Optimal Intensity of Ural Anticoagulant Therapy After Myocardial Infarction
}

\author{
AIDA J. AZAR, PHD, + SUZA INE C. CANNEGIETER, MD, JAAP W. DECKERS, PHD,* \\ ERNEST BRIËT, PHD, $\ddagger$ PAUL F. M. M. VAN BERGEN, PHD, † JAN J. C. JONKER, MD, $†$ \\ FRITS R. ROSENDAAL, PHD $\$$ \\ Rotterdam, Leiden, The Netherlands
}

Objoctives. This study attemapted to determine the optimal Intensity of anticaagulant therapy in patlents after myocardial Infarction.

Background. Treatment with oral anticoagulant therapy entails a delicate balance hetween over- (risk of bleeding) and under. anticoagulation (risk of thromboemboli). The optimal Inteasity required to prevent the occurrence of either event (bleeding or thromboembolic) is not known.

Methods. A method was used to deterwine the optimal intensity of anticoagulant therapy by calculating incidence rates for either event associated with a specific international normalized ratio. The numerator included events occurring at given international noribalized ratios, and the denominator comprised the total observation time.

Resulk. The study population inchided 3,404 myocardial infarction patients earolled in the ASPECT (Anticangulants in the Secondary Prevention of Events in Coronary Thrombosis) trial. Total treatment was 6,918 patient-years. Major bleeding oceurred in 57 patients (0.8/100 patient-years), and thromboembolic complications in 397 (5.7/100 patient-years). The incidence of the

Findings of the three most recently performed trials following myocardial infarction demonstrated that intensive anticoagulant therapy reduced the rate of reinfarction by $34 \%$ to $55 \%$, stroke by $40 \%$ to $55 \%$ and total mortality by $10 \%$ to $26 \%$ (1-3). In these investigations, a high quality of anticoagulation was achieved, because $63 \%$ to $74 \%$ of the prothrombin time measurements were withiil the therapeutic international normalized ratio range between 2.5 and 5.0 .

Although the investigations demonstrated beneficial effects of anticoagulant treatment in myocardial infarction

From the "Thurakcenter, Department of Cardiokmy, University Hexpital Dijkzigt. Erasmus Univeristy of Ritterdam, Roterdatm ASPECT Coordinating

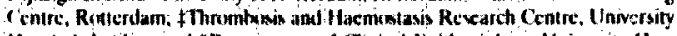

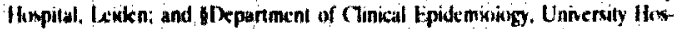
pital, Ievien. The Netherlands. This work was supported by a grant frim the Pracienticlonds. Ihe Nethertands (2K-47\%) and a sutwidiany grant from The Netheriands. Thrombusis Foundation, The Netherfands.

Manuactipt recened February 22 1945: revised manuscript received Nowem-

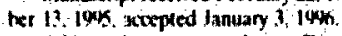

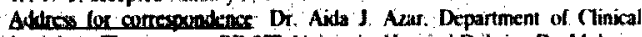

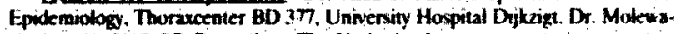

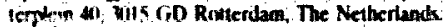

combined outcome (bleeding or thromboembolic complications) with international normalized ratio <2 wa 8.0100 patient-years (283 events in 3,5:9 patient-years), with intematlonal sormillsed ratios between 2 and 3,3.9/100 patient-years (33 wents to 898 patient-years); $3.2 / 100$ pattent-years ( 87 events in 1,775 pattentyears) for International normallwed matlos between 3 and of 6.6/109 patieal-years (37 events in 564 patient-years) for internathotal normalized ratios between 4 and 5 ; and 7.7/109 patientyears (14 ivents in 182 patlent-years) for international nermalized ratios >5. After adjustment for achleved internationd normalized ratio levels, significant predictors were higher levels of systolic blood pressure and age.

Conclusions. If equal weight is given to hemorrhagic and thromboembolic complications, these results sagest that the optimal intensity of long-term anticnagulant therapy for myocar: dial infanction patients lies between 2.0 and 4.0 international normalized ratio, with a trend to suggest an optimal intensity of 3.0 to 4.0.

(J Am Coll Candial 1996;27:1349-55)

survivors, these trials have not established the optimal intensity of anticoagulant therapy for two major reasons. Fisst, the intensity of anticoagulant therapy actually achieved was not taken into account, and, second, the target level of anticodgulation was chosen arbitra ily. For the same reasons, randomized trials conducted to compare two intensities of oral anticoagulant therapy offered litile information on the optimal intensity of anticoagulant therapy (4). Therefore, it is not known what intensity of anticoagulant therapy offers the optimal benefit-risk ratio, that is, the optimal balance between prevention of thromboembolic events and bleeding complications.

To determine this optimal intensity of anticoagulant therapy, we quantitatively cvaluated the occurrence of hemorrhagir as well as arterial thromboembolic complications with respect to the intemational normalized ratio level preceding the event, thereby enabling the calculation of international normalized ratio-specific incidence event rates. The study population comprised 3,404 myocardial infarction patients randomized to anticoagulant therapy of placebo. 


\section{Methods}

Patlents. The ASPECT (Anticoagulants in the Secondary Prevention of Events in Coronary Thrombosis) subjects comprised the study group. This trial has been described in detail elsewhere (3,5). In short, ASPECT was a randomized, doubleblind, placebo-controlled, multicenter, clinical trial that compared anticoagulant therapy with placebo on mortality and cardiovascular events in myocardial infarction patients. This trial demonstrated that anticoagulant therapv targeted at international ncrmalized ratio 2.8 to 4.8 reduced the rates of recurrent myocardial infarction by $53 \%$ and intracranial events by $41 \%$. The present analysis was planned as an ancillary one before study termi.atuon.

Hospital survivors of acute myocardial infarction were screened for eligibility just before hospital discharge. After giving informed consent, patients were randomly assigned to ireatment with oral anticuagulant therapy or matching placebo. From September 1, 1986 until December 31, 1991, 3,104 patients entered the trial. Their mean age was 61 years, $20 \%$ were women (mean age 65 years), fewer than $8 \%$ had diabetes, $25 \%$ had been treated with thrombolytics, and $95 \%$ of the patients were in Killip class 1 or II during hospitalization. Fewer than $2 \%$ of the patients had undergone a revascularization before study entry, and $9 \%$ had suffered a previous myocardial infarction. Medication at hospital discharge included beta-adrenergic blocking drugs in $50 \%$ and angiotensinconverting enzyme inhibitors in $9 \%$. Because the present analysis considered only the period under trial medication, the mean follow-up per patient was 2.1 years.

Oral anticoagulation and dose adjustment. The larget anticoagulant range was 2.8 to 4.8 international normalized ratio $(6-9)$. Individual dose adjustments were guided by the prothrombin time measurements obtained at regular intervals at 1 of the 19 participating anticoagulant clinics. Anticoagulant treatment consisted of phenprocoumon, acenocoumarol or matching placebo tablets. Double-blinding was maintained at the anticoagulant clinics by use of a computerized dosage algorithm that automatically converted prothrombin times to sham values within therapeutic range in placebo-treated patients.

At each follow-up visit to the anticoagulant clinic, a short history was taken, and a blood sample was drawn for determination of the inrombotest, a modified prothrombin time test (1). Patients were scen at the initial (randomization) visit and or a weokly basis thereafter until the prothrombin time measurements were within the specified target range. The interval between visits was subsequently prolonged up to a maximum period of weeks. Patients requiring frequent dosage adjustments were seen more regularly. At the end of trial in June 1992, trial medication was discontinued in all patients.

Defiaition of ctinical events. The following clinical events wert considered: major bleeding or thromboembolic compli. cations. Bleeding was considered major if it 1) led to death, 2) was clinically suspected of proven intracranial (cerebrovas: cular event leading to death within $24 \mathrm{~h}$ was considered to be caused by intracranial tleeding unless the findings on computed axial tomography scanning indicated otherwise; in all other instances, the diagnosis of an intracranial hemorrhage had to be confirmed by findings on CAT scan (11), or 3) led to hospital admission for treatment of bleeding (hospital admission for diagnostic purposes only was not considered a criterion for major bleeding).

Thromboembolic complications included 1) instantaneous or sudden death occurring within $\mathrm{l}$ h after onset of symptums; (2) recurrent myocardial infarction documented by at least two of the following $(12,13)$ : a) history of chest discomfort of at least $30 \mathrm{~min}$ duration; b) serial enzyne pattern typical for myocardial infarction with at least one cardiac enzyme excecding twice the upper limit of nurmal: or c) the devclopment of new $Q$-waves lasting $>0.03 \mathrm{~s}$ or of $\mathrm{Q}$-wave equivalent [ $R>0.03 \mathrm{~s}$ in $V_{1}$ and $R / S>1$ in $\left.V_{2}\right]$ ) on the standard 12-lead electrocardiogram (ECG); myocardial infarction was also diagnosed when death occurred within 28 days after hospitalization for recurrent myocardial infarction; 3) cerebral infarction, classified according to internationally accepted criteria and diagnused on the basis of the CAT-scan findings (11); and 4) other arterial thromboembolic complications.

Information on clinical events was obtained directly from the patients when they visited the anticoagulant clinic or from their general practitioners. In case of hospitalization, additional information was retrieved from the hospital records. The diagnosis and classification of clinical events were established by the Mortality and Morbidity Classification Committee of the ASPECT trial, who independently reviewed the clinical course of each case on the basis of a revies: "f a standardized patient report before study termination. Ine committee members were unaware of treatment assignment and were not informed of actual prothrombin time measurements.

Assessment of optimal intensity. Incidence rates were calculated for different achieved intensities of anticoagulant therapy (4). Intervals of 1.0 international normalized ratio were used. As the lowest reference interval, we used international normalized ratio $<2$, which includes the patient-time of all patients or placebo and actual measurements of international normalized ratio $<2$ in patients receiving anticoagulant drugs (5\%). This reference category represents absence of treatment. Only those international normalized ratio measurements that were obtained during the trial medication period were considered. The uptimal intensity of anticoagulant therapy will lie at the level at which the incidence of bleeding or thromboemboli is lowest, that is. where the incidence of complications, whatever their type, is Iowest. This approach has been explained in detail previously (4).

Numerator dats: events. The numerator of the international normalized ratio-specit: incidence rate was composed of events (bleeding or thrombosmbolism) occurring at a given interiotional normalized ratio intensity. If the intemational normalized ratio measurement for the date of event was not available, the last intemational normalized ratio measurement oblained within a maximum period of 28 days before the event 
Table 1. Selected Demographic, Baseline and Randomization Characteristics

\begin{tabular}{|c|c|c|c|}
\hline & Anticragulant & Placdun & Total : \\
\hline No. of patients (\%) & $1,700(100)$ & $1.704(100)$ & $3,414(100)$ \\
\hline Mean age, years (SD) : & $61(11)$ & $61(11)$ & $61(11)$ \\
\hline Gender $(\%)$ & & ' & : \\
\hline Male & $1.370(81)$ & $1,350(79)$ & $2,270(80)$ \\
\hline Female & $330(19)$ & $354(21)$ & $684(20)$ \\
\hline \multicolumn{4}{|l|}{ Trial medication $(\%)$} \\
\hline Phenprocoumon & $9.30(55)$ & $935(55)$ & $1,465(55)$ \\
\hline Acenocoumarol & $770(45)$ & $769(45)$ & $1,539(45)$ \\
\hline Mean SBP. mm Hy (SD) & $119(16)$ & $114(16)$ & $119(16)$ \\
\hline
\end{tabular}

SBP - systolic blowd pressure at howpital discharge.

was taken from the hospital records. International normalized ratio measurements were considered nissing in all other instances Patients who were treated with placebo were included in the analysis because their achieved international normalized ratio intensity corresponding to "lack" of anticoagulation is of course known and corresponds to an international normalized ratio of 1 at the time of an event as well as at all other times. In a subsequent, stricter analysis, we only included events for which an international normalized ratio measurument obtained no more than 3 days before the event was available, whereas all others whie considered missing (except for the placebo patients).

Patients were censored when an event was reached after cessation of trial medication or at the end of follow-up, on June 30, 1992, whichever occurred first. In case patients experienced more than one event, only the first was considered. Four patients with major bleeding from an invasive interventional procedure during hospitalization were not included in the analysis.

Denominator data: international normalized ratio-time. The denominator of the international normalized ratio-specific incidence rate comprised the sum of patient-days within specific international normalized ratio intervals (4). In order to calculate the time cach patient was within an international normalized ratio-specific range, we assumed a linea interpolation between adjacent international normalized ratio measurements (5). In addition; in case the intersol between two consecutive international normalized ratio measurements $\mathrm{ex}$ ceeded 56 days, this time period was not included in the present analysis, because a linear change over this long period of time becomes unrealistic. Patients who used placebo were considered to have international normalized natio measurements below 2 during the total period of follow-up.

Poisson regression analysis. The relative risk of bleeding or thromboembolic events associated with international normalized ratio-specific intenals after adjustment for age, sex. type of coumarin congener and blood pressure was calculated with Poisson regression analysis (14). The Poisson was used to model incidence rates for grouped data. Age and systolic bluod pressure measured during hospitalization for the index myocardial infarction, were categrized on the basis of the median
Table 2 Incidence of Major Blecding During Follow-Up

\begin{tabular}{|c|c|c|c|}
\hline$\therefore$ & $\begin{array}{l}\text { Antiandgulant } \\
(n=1,700)\end{array}$ & $\begin{array}{l}\text { Placetuo } \\
(n=1,744)\end{array}$ & Total \\
\hline Number of patientyears & 3,430 & 3,468 & 6,918 \\
\hline Intracranial bleeding & 14 & 1 & 15 \\
\hline Fatal & 7 & 0 & 7 \\
\hline Nunfatal & 7 & 1 & $\because 8$ \\
\hline Extracranial bleeding & 37 & 5 & 42 \\
\hline Fatal & 2 & 0 & $\boldsymbol{Z}$ \\
\hline Nonfatul & 35 & 5 & 40 \\
\hline Tortal major hleceding* & $\$ 1(1.5 / 1010 y)$ & $h(1+2 / 1 \mathrm{u}) \mathrm{p})$ & $57(0 \mathrm{~N} /(\mathrm{N}) \mathrm{py})$ \\
\hline
\end{tabular}

-Int racranial or cxiractanial blecding, whichever occurred lirst. py = patientyears.

value (below or above of years of age and $120 \mathrm{~mm}: \mathrm{Hg}$. respectively). The incidence rate ratios obtained from the model may be viewed as relative risks, that is, the risk for an event relative to the reference risk factor category controlling for the other risk factors. The $95 \%$ confidence intervals were obtained from the Poisson distribution.

\section{Results}

A total of 1,700 patients were randomized to anticoagulant therapy (with 3.430 patient-years of follow-up), and 1,704 to placebo (with 3,488 patient-years of follow-up); $55 \%$ of the patients received phenp: $n c 0 u m o n$, ar.J $45 \%$ acenocoumarol (Table 1).

The incidence of major bleeding is shown in Table 2 . Fify-seven cases of major blecding (0.8/101) patient-ycars) ocuurred, 51 in the anticuagulant (1.5/100 patient-years) and 6 in the placebo group ( $0.2 / 100$ patient-years). This results in a relative risk for major bleeding of 8.6 with a $95 \%$ confidence interval of 3.7 to 20.1. Fatal bleeding (nine patients) was observed only in the anticoagulated group (0.3/100 patientyears). The most frequent sites of major extracranial bleeding verc the gastrointestinal tract $(26$ with anticoagulation and 2 with placebo) and muscular hem toma in 10 of the anticoagulated group.

The incidence of thromboembolic events is presented in Table 3. A total of 397 thrombuembolic complications $(5.7 / 100$ patient-years) occurred; of which 118 were fatal. One hundred twenty-seven thromboembolic events (3.7/100 patient-years) were observed in the anticoagulation group, and 270 with piacebo (7.7/100 patient-years), resulting in a relative risk for major thromboembolic complications of 0.48 with a $95 \%$ confidence interval of 0.39 to 0.59 . The major thromboembolic events included sudden death (69 patients), recurrent myocardial infarction (293 patients) and cerebral infarction (34 patients).

International normalized ratio measurements obtained at hospital admission or within 3 days before the occurrence of major bleeding were available in 42 cases ( 6 of 6 placebo and 36 of 51 anticuagulation patients) and in 55 patients ( 6 of 6 
Table 3. Incidence of Thrombiembilic Hvenls During Follow. Up

\begin{tabular}{|c|c|c|c|}
\hline & Aniktugulam! & Placclat & \\
\hline & $(n-1.2(n)$ & (n 1.714$)$ & Thtal \\
\hline $\begin{array}{l}\text { Number of } \\
\text { patient yean }\end{array}$ & $3.4,4)$ & 3.4.4. & 6.91K \\
\hline Surdden death & 35 & 34 & by \\
\hline Recurtent -MI & 8 & 397 & 293. \\
\hline Fatal & 16 & $\because$ & 47 \\
\hline Nonfatad & 70 & 176 & 246 \\
\hline Cerebral infarcion & 6 & 28 & 34 \\
\hline Fatal & 0 & 2 & 2 \\
\hline Nonfitial & 6 & 36 & $\because$ \\
\hline 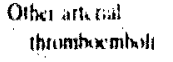 & 1 & 4 & 5 \\
\hline 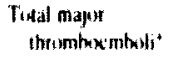 & 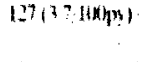 & $27017,7(104, n !$ & $3 n(5,7)(x+p y)$ \\
\hline
\end{tabular}

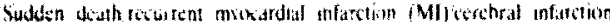

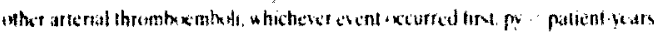

placebo and 49 of 51 anticoagulation patients) within a time frame of 28 days. Intcrnational normalized ratio neasurements within 3 dass from thromboembolic complication were obtained in 294 paticnts $(270$ of 270 placebo and 24 of 127 antcoagulation pattents) and within 28 davs in 375 paticnts (270 of 270 placcho and 165 of 127 anticodgulation patients). The thal number if patient-years within intel talional normalized ratio-specific intervals for the combined evert (bleeding or thrombemboli) wne $\mathbf{3 . 5 5 9}$ patient-ve'ars (international normalized ratio 2), 838 paticul-years (intornatiore? normalieed ratio 2 wo 3) 1,775 paticnt-years (international normalized ratio 3104 ), 564 patient-vears (international nomalized ratio 4 to 5) and 182 patient-years (international normalized ratio $>5)$ for international normalized ratio measurements obtained within 3 or $2 \times$ daws from the event.

International normalised ratio-specific incidence rates havid on measurements whedined within 2k days of major hlecding and thrombembolic complicatesn are prewented in Figure $I$ and in Tahle 4 . The international nornalized ratio-

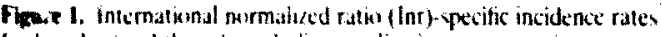

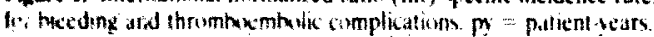

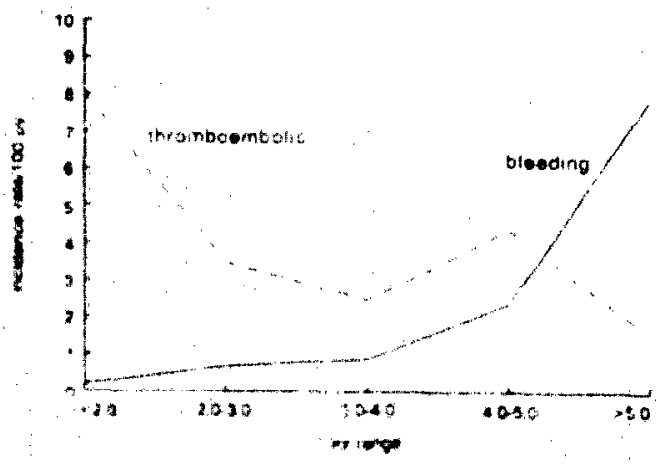

Tuble 4. Incidence of Events Within hite Specific International Normalized Ratio Intervals

\begin{tabular}{|c|c|c|c|}
\hline INR & Puents & Patient-Ycars & Incidence Rate \\
\hline \multicolumn{4}{|c|}{ Hemorthugit } \\
\hline 42 & 8 & $3,(6) 3$ & $(1.2 / 100 / p y$ \\
\hline $2-3$ & 5 & 757 & $0.7 / 100 / p y$ \\
\hline $3-4$ & 16 & 1,811 & $0.9 / 100 p y$ \\
\hline $4-5$ & 14 & 576 & $2.4 / 100 \mathrm{py}$ \\
\hline 25 & 12 & 151 & 7.9/10upy \\
\hline \multicolumn{4}{|c|}{ Thrombermbolic } \\
\hline$\therefore$ & $3 k_{2}$ & 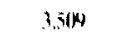 & soldolloy \\
\hline 3.1 & 27 & 771 & $3.5 / 100 \mathrm{py}$ \\
\hline $3-4$ & 41 & 1.6 .54 & $25 / 101 \mathrm{py}$ \\
\hline 4.5 & 23 & 528 & 4.4/llingy \\
\hline. .5 & 2 & 120 & 1.6. 1)(kpy \\
\hline \multicolumn{4}{|c|}{ 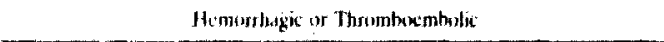 } \\
\hline$\because 2$ & $2 \times 3$ & $5,5,59$ & X.t:10) \\
\hline $2-3$ & 32 & 8.38 & $3.8 / 110 p y$ \\
\hline 34 & 57 & 1,775 & $3,2 / 100) \mathrm{py}$ \\
\hline 4.5 & .37 & 564 & h.th/I(H)py \\
\hline .5 & 14 & $1 \times 2$ & $7.7 / 10$ (py \\
\hline
\end{tabular}

INR - intcrnational nermalized ratio; $p y=$ - patient-ycars.

specific incidence rate of bleeding was lowest, 0.2 per 100 patient-years ( 8 events in $3,6,03$ patient-years), at anticoagulant intensities less than 2 international normalized ratio and was highest, 7.9 per 100 patient-years $(12$ events in 151 patientyears). at anticoagulant intensities exceeding the value of 5 . On the wher hand, the incidence of thromboembolic complications was highest, 8.1$)$ per 100 paticnt-years (282 events in 3,509 paticnt-years), for anticoagulant intensities less than 2 international normalized ratio and was lowest, 1,6/100 patient-years (2 events in 126 patient-years) for international normalized ratio intensities exceeding the value of 5 .

The optimul anticoagulant intensity. The incidence of the combined outcome (bleeding or thrombermbolic complicarions) occurred in 423 cases ( $6.1 / 100$ patient-years). The incidence was lowes:, $3.2 / 100$ patient-years $(57$ events in 1,775 patient-years). at international normalized ratio values $b c$. tween 3 and 4 In snational normalized ratio-specitic incidence rates with corresponding 95\% confidence intervals, baxd on international normalized ratio measurements oh. tained within 28 days from event. are presented in Figure 2 , for the combined events of bleeding as well as thromboemboli. The incidenec of complications was highest at international normalized ratio values below 2 and above 5 . The intensity at which the intemational normalized rastio-specific incidence rates of the curve sowest is the optimal intervity: between 3 and 4 international normalized ratio. Sinvilar results were Whaned when the analyois was repeated for international normalued ratio mesurements obtained within 3 dav from the exent

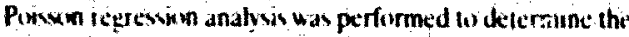
independent: af owent iblecting or thrombermbolic) oser 


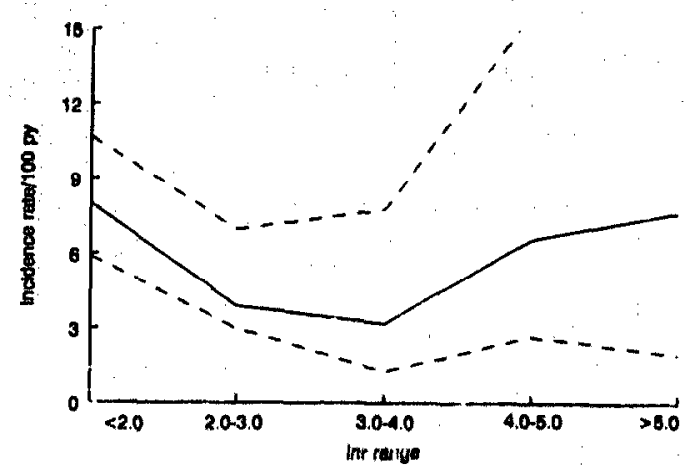

Figure 2. International normalized ratio (Inr)-specific incidence rates for the combined event (bleeding or thromboembolic complications). Dashed lines indicate $95 \%$ confidence interval.

ciated with age, sex, systolic biood pressure at discharge and type of coumarin congener; results, after controlling for achieved international normalize 1 ratio intensities, are presented in Table 5: Significant predictors for major bleeding or thromboemboli included higher systolic blood pressure and more advanced age. The risk of bleeding was higher in women.

\section{Discussion}

The optimal intensity, the intensity of anticoagulation at which the incidence of hemorrhages as well as thromboemb!)lism was lowest, appez: id to be located between international nomalized ratio 2.0 and 4.0 , with a trend to suggest an optimal intensity between 3.0 and 4.0 international normalized ratios. In this range, the risk of bleeding was relatively low, amountin: to 5 major bleeding complications per 1,000 treatment-years,

Tahle 5. Multivariate Analysis of Other Risk Factors for Hemorrhagic and Thrombembolic Complications*

\begin{tabular}{|c|c|c|}
\hline & $\begin{array}{l}\text { Hemorthagic } \\
\text { Events RR } \\
(95 \% \text { Cl) }\end{array}$ & $\begin{array}{l}\text { Thrombsembrilic } \\
\text { Events RR } \\
\text { (US: C C) }\end{array}$ \\
\hline \multicolumn{3}{|l|}{ Age (years) } \\
\hline$<\boldsymbol{6}) !$ & 1.0 & 10 \\
\hline$\geq 60$ & $1.5(0.8-28)$ & $\mid n(1) 2-21)$ \\
\hline \multicolumn{3}{|l|}{ Gender } \\
\hline Malct & 1.11 & 10 \\
\hline Furnalk & $1.7(09-3.2)$ & 1. $1\{0, n-1,5\}$ \\
\hline \multicolumn{3}{|c|}{ Anticougulant congeter } \\
\hline Thenpiraument & I.1 & 10 \\
\hline Lenkocinumarul: & $0.9(0,5-1,6)$ & $1.0(0.7-1.5)$ \\
\hline \multicolumn{3}{|l|}{ SHP (mm lig) } \\
\hline $13 n$ & 1.0 & 1.0 \\
\hline $\boldsymbol{x}$ & $20(1.1-1.6)$ & $3,3(2-2-4,4)$ \\
\hline
\end{tabular}

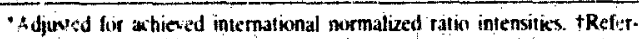

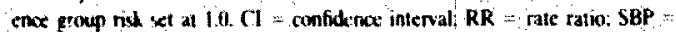

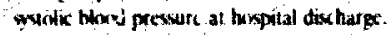

while the reduction in thrombonbolic complications, relative to international normalized ratio intensitie below 2 , was $70 \%$. Such a narrow range for optimal anticougulation could be achieved in only approximately $20 \%$ of patient-years in this study, although the quality of long-term anticoagulant therapy achievable in the Netherlands on a population basis is probably unique. The broader range (international normalized ratio $\mathbf{2 . 0}$ to 4.0 ) could be attained in $75 \%$ of patient-years and was almost as effective. Such levils may be more readily achievable in general.

Intensity of anticoagulation and riak of bleeding. The riak of bleeding associated with anticoagulant therapy in patients with as well as without coronary hi ant disease is well recog* nized and has led to the conduct of several trials that compared the efficacy of different intensities of oral anticoagulant therapy (15-17). So far, however, these trials have been unable to provide the "true" optimal anticoagulant intensity. The main reason, of course, is that achieved anticuagulant intensity is not constant and will invariably fluctuate around the prespecified target level hinging on particular characteristics of the patient under treatment as well as on extraneous features related to the administration and monitoring of the therapy.

Given the acknowledged relation between incidence of bleeding complications and high anticoagulant intensities (1522), it is surprising that few attempts have been made to quantify this association. In one recent population study (23) in which the achieved intensity of anticoagulant therapy was analyzed in 6,814 patients, a $42 \%$ increase in the risk of major bleeding was reported for every rise of 1.0 in the international normalized ratio. In another recent analysis, a nested casecontrol study of 565 patients starting outpatient therapy with warfarin by Lindefeld et al. (20), the odds ratio for major bleeding increased with increasing prothrombin time to conirol ratios. In the present analysis, the risk of major bleeding ixcreased gradually with elevation in the intensity of anticoagulation achieved. The risk was increased $80 \%$ when international normalized ratio intensities were between 4 and 5 as compared to intensities below 2 intemational nomalized ratio, $\checkmark$ hile the risk was increased almost fivefold when international normalized ratio intensity exceeded 5 .

Intensity of anticiagulation and risk of thromboembolle complications. Although it seems reasonable to assume an increascd risk of thromboembolic events with less intense anticoagulation, this conclusion cannot casily be extracted from the literature. In addition to the previously mentioned methodological issues, the relatively small size of some studies is another limiting factor. Evidence for strong effects of anticoagulant therapy on thromboembolic complications were obtained in the three most recently conducted placebocontrolled trials: the Sixty-Plus (1), WARIS (2) and ASPECT (3). The intensity of treatment in these was characterized by a prothrombin time prolongation of 2.5 to 5.0 international normalized ratio. These trials convincingly demonstrated that a substantial reduction in myocardial infarctions and cerebro. vascular events can be achieved with this type of therapy: 
Limitatlons of our study. A drawhack of our analysis is that we were unable to obtain international normalized ratio measurements at the time of the event in every instance. in particular for the thromboembolic events. Prothrombin time measurement at the moment of the cvent was not specifically required by the study protocol and, therefore, was not always reported by the investigator. In bleeding patients on oral anticoagulant therapy, an intemational normalized ratio measurement will be performed far more often than in a patient with a myocardial infarction. This is unfortunate but affects only the power of the study, not the validity, because it is not conceivable that the decision to perform or not perform an international normalized ratio in a paticnt with myocardial infarction is dependent on his or her (known) international nomalized ratio, It should he noted that double-blinding was still maintained at the time of hospital admission. When we restricted the analysis to events with an international normaliaed ratio at or shortly before ( $<3$ days) the event, international normalized ratio data were available in only about $34 \%$ of the patients taking anticoagulants (and all placebo patients). When a less stringent criterion was used, and international nonnalized ratio measurements up 1028 days before the event were accepted as representing the international normalized ratio at the cvent, we had information on $87 \%$ of the anticoagulation patients (and again in all placeto patients). Although both analyses are obviously suboptima', they lead to the same result of a nadir of events at international normalized ratio values between 2 and 4 . Although these findings will need to be cenfirmed in larger series, these first analyses of the achieved intensity of anticoagulant therapy in myocardial infarction patients point to an optimal intensity of 2104 international normalized ratio, with a trend to suggest that the optimum intensity lies between 3 and 4 international normalized ratio.

In this analysis, the optimal intensity of anticoagulant therapy was defined as the level at which the incidence of the sum of bleceding or einbolic complications was lowest, and they were equally considered. We $r$ alize that this is not always realistic, and it is dependent on the severity of the actual complication, cardiac or ncurologic. The actual rate of embolic is well as hemorrhagic complications is therefore given here.

Prediction of events. In line with findings reported by others, the current analysis confirmed the independent contribution of higher systolic blood pressure to increased bleeding tendency during anticoagulation therapy (24). High blood pressure was also associated with increased thromboembolic complications. Our results confirm a recent observation of a higher blecding incidence in elderly and female patients (2325). In contrast to findings of another analysis that employed the same quantitative approaci as cutrent'y described (23), we were unable to confirm the association of the use of acenowoumarol with increased blecding lendency.

Coaclusions. In conclusion, the eptimal therapeutic range for long-term oral anticoagulant th srapy in myicardial infarction patients has been a matter of intense debale for more than 30 year (26). Finding in this lay,e cohurt provide a quantitative basis to locate the optima therapeutic anticoagulant intensity within the international normalized ratio range of 2.0 and 4.0. assuming that equal weights are given to hemorrhagic and thromboembolic complications, with a trend to suggest an optimal intensity of 3.0 10 4.0. In this range, sonewhat lower than the targeted anticoagulant intensity in the most recent secondary prevention trials (27), the incidence of major bleeding during long-term anticoagulant therapy is relatively small, and a substantial reduction in the rate of thromboembolic events is achieved.

\section{References}

1. The Sixty Plus Reinfarction Study Restarch Gronp. A double-blind trial to usess kny-term oral anticoagulant therapy in slikerly paticnts after myocardial infarction. I aricet 14:35;2:989-93.

2. Smith P. Arnesen H. Holme I. The tfled ne warlarin on mortality and reinfarclion after mycxardial infarction. N Engl $J$ Med Iy91:323:147-52.

3. Anticuagulants in the Sccondary Prevention of Events in Coronary Thromhovis (ASPECT) Rexarch Group. Effeci of long-term anticoagulant treatment on mortality and cardiovascular norbidity after myocardial infarction. Laricet $1994 ; 1: 499-503$

4. Rinendeal FR, Cannepieter SC, van der Meer FJM, Britt E. A method to determine the optimal intensity of oral anticoagulant therapy. Thromb Haemonas 194) 3:69:236-39,

5 Arar AI Deckers JW Rosendaal FR et al. Assessment of therapeutic achievement in a long-term anticoagulant trial in post-myocardial infarction patients. Thromb Hemostas 1994;72:347-51.

6. locliger EA. Laburatory control, optimal therapeutic ranges and therapeutic qualiuy control in oral anticoagulation. Acta Hacmatol (Basel) 1985;74: $125-31$

7. Loeliger EA, Brockmans AW. Optimal therapeutic anticoagulation. Haemoxtasis 1485:15:283-42.

x. Loeliger EA. ICSH/ICTH recommendations for reporting prothrombin time in was anticougulant controt. Thromb Hacmostas 1985;53:155-6.

9. Leweliger EA. The optimal therapeulic range in oral anticoagulation. Hisfory and propenal. Thrumb Haemostas 1979;42:1141-52

117. Cowen PA. Thrombotest. A new method for controtling anticuagulant thirapy. Lancet 1959;2:754-8.

11. The Ad Hoc Commiltec on the Classification and Outline of Cerebrowascular Dixase. II (Chairman Milkan CH). Stroke 1975:6:566-616.

12. The Criteria Committec of the New York Heart Astociation, Discase of the Heart and Blexol Vescels; Nomenclature and Criteria for Diagnesis, 7th ed. Buston: Little, Brown, 1973.

13. The Criteria Committee of the New York Heart Association. Nomenclature and criteria for diagnosis of diseases of the heart and great vessels, 8th ed. Boston: Little, Brown, 1979.

14. Greenberg RS, Kleinbaum DG. Mathematical modeling strategies for the analysis of epidemiologic research. Annu Rev Public Health 1985;6:22145.

15. Hull $R$, Hirsh J. Jay $R$, at al. Dilletent intensitics of oral antikoggulant therapy in the treaiment of proximal-vein thrombois. N Engl $J$ Med $108: 307: 1676-81$

16. Huli R. Delmore T. (arter C, et al. Adjusted subcutaneous heparin versus warfarin wodium in the long-lerm treatment of venous thrombosis. N Engl 3 Med 1982;3) $: 189-44$

17. Turpic AGG, Hirsh J. Guntiensen J. Nelson H. Gent M. Randkmixd camparisen of twas intensitics of oral anticasgulant therapy after tissut hetin valve ieplacement. Lancet 1 \%\$; $1: 12 \$ 2-5$

IH. Sutur JN. Skck JO. Mamo LAR Gallus AS Triul of diferent intensites in anticiagulation in patients with pronthetic heant values. N tingl I Med $1(x) 1,321,428-32$

14. Fortst J. A 7 yeat analyon of hemorrhage in patients on king-1erm anticiugulant Ireatmont. B thart 1 1974, 2:138-12.

91. Landefeld CS. Rınenblati MW, Goldman L Bteding in culpatients Heated with wafarin relation to the protheombin time and important femediatle

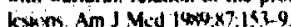


21. Petti DB, Strom BL. Melmon KI. Duration of warfarin anticoagulant therapy and the probabdities of recurrent thrombuembolism and hemorrhages, An J Med 1986;81:235-9:

22. Second report of the Sixty Plus Reinfarction Study Renearch Oroup. Risks of long-term oral anticoagulant therapy in elderly patients after myocardial infaretion. Lancet 1982;1:64-8.

23. van der Meer FJM. Rosendaal FR, Vandenbroucke JP, Briet E. Bleeding complications in oral anticoagulant therapy: an analysis of risk factors. Arch Intern Med 1993;153:1557-62.

24. Launbjerg J, Egeblad H; Heaf J, Nielsen NH, Fugleholm AM, Ladefoged
K. Bleeding complications to ofal unticoagulant therapy: multivariate analyais of 1010 treatment years in 551 outpatients. I Intern Med $1991 ; 229: 351-5$.

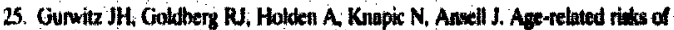
long-1crm ord anticougulant therapy. Anch Intern Med 1988; 148:1733-6.

26. Hins J, Levine M. Confusion iwer the therapeutic range for monitoring ural

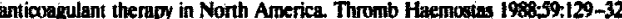

27. Loeliger EA. Therapeutic target values in oral anticoagulation-justrication of Dutch policy and a warning againat the socalled moderate-intensity regimens. Ann Hematol 1992;64:60-5. 